\title{
Metastatic Malignant Neoplasm in the Neck
}

National Cancer Institute

\section{Source}

National Cancer Institute. Metastatic Malignant Neoplasm in the Neck. NCI Thesaurus. Code $C 8528$.

A malignant neoplasm that has spread to the neck region from a malignancy in a local or distant anatomic site. 